\title{
LEFT ATRIAL AND PULMONARY CAPILLARY VENOUS. PRESSURES IN MITRAL STENOSIS
}

\author{
BY \\ R. G. EPPS AND RICHARD H. ADLER* \\ From the Department of Cardiology, Brompton Hospital \\ Received February 10, 1953
}

\begin{abstract}
A method of measuring pulmonary " capillary" pressure by wedging a catheter into a terminal branch of a pulmonary artery was introduced by Hellems et al. in 1948. To differentiate this from pressures recorded in a blocked pulmonary vein (e.g. through an atrial septal defect) this pulmonary " capillary" pressure will be referred to as pulmonary capillary venous pressure (P.C.V.P.), following the lead of Lagerlöf and Werkö (1949). Subsequent investigations have produced conflicting evidence concerning the interpretation and accuracy of such pressure measurements, and this report presents the results of a new method used to investigate the relationship between P.C.V.P. and left atrial pressure.
\end{abstract}

Dow and Gorlin (1950) found a close correlation between P.C.V.P. and left atrial pressure in dogs; the two pressures also varied directly under abnormal conditions. Several investigators have found the P.C.V.P. to be higher than the pressure in the left atrium, considerably so in some instances (Hellems et al., 1948, 1949; Lagerlöf and Werkö, 1949; Calazel et al., 1951 ; and Ankeney, 1952). Ankeney has recently questioned whether phasic variations in P.C.V.P. records reflect similar phasic pressure changes in the left atrium, and suggests that the true P.C.V.P. is essentially devoid of phasic variations. Opinion among investigators also varies with regard to the significance and interpretation of the waves seen in P.C.V.P. tracings.

So far all published attempts to record pressures from a blocked pulmonary artery and from the left atrium simultaneously have been in dogs under general anæsthesia or in human subjects with atrial septal defect. In this investigation the problem has been tackled in the conscious human subject in the absence of a septal defect. Certain patients with mitral valve disease were selected for this study, in view of the practical importance of measuring the P.C.V.P. in that condition.

It is common knowledge that the tracheal bifurcation and left atrium are in close proximity, and that an enlarged left atrium in mitral valve disease may widen the carina and compress the left main bronchus. Post-mortem examinations confirmed the fact, first demonstrated by Allison (1952) in this country, that a needle could be introduced through the left main bronchus into the left atrium without endangering any nearby vital structure.

Method. After studying relevant anatomy in the cadaver, a No. 22 gauge needle, $5 \mathrm{~cm}$. long, was selected for the left atrial puncture. The needle was attached to the distal end of a metal bronchoscopic suction tube. A polythene catheter inside the metal tube connected the needle to the recording machine. Fig. 1 illustrates the position of a three-way tap that provided the essential means of recording immediately consecutive pressures from the left atrium and from a blocked peripheral pulmonary artery.

Cardiac catheterization was performed by the standard method of Cournand on the conscious patient 30 minutes after oral administration of 3 grains of sodium amytal and 0.5 grains of codeine phosphate. Heparin, 5000 units $(50 \mathrm{mg}$.), was injected through the catheter. Pressures were recorded in $\mathrm{mm}$. $\mathrm{Hg}$. by means of a Sanborn electromanometer and a direct writing multichannel

* Work undertaken during the tenure of a fellowship from the Dazian Foundation for Medical Research, U.S.A. 298 
oscillograph with simultaneous electrocardiogram. Mean pressures were obtained by electrical integration of the oscillograph tracings. An adjustable mechanical damper was used to eliminate artefacts in the pressure records. The zero point for all pressures was the sternal angle.

The pulmonary artery pressure and P.C.V.P. were recorded under resting conditions and the catheter then withdrawn to a main branch of the pulmonary artery. Blood samples were taken simultaneously from the brachial artery and pulmonary artery, and the oxygen content measured by the method of Van Slyke. The oxygen consumption was then estimated by means of a closed circuit spirometer.

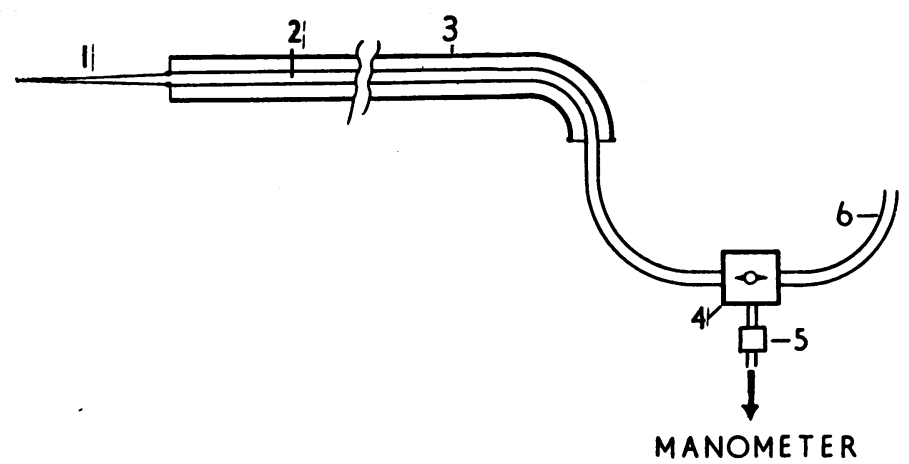

FIG. 1.-Arrangement of apparatus to record immediately consecutive P.C.V.P. and left atrial pressure (see text). (1) Needle in left atrium. (2) Polythene catheter. (3) Metal bronchoscopic suction tube. (4) Three-way tap. (5) Mechanical damper. (6) Intracardiac catheter to blocked peripheral pulmonary artery.

The patient was prepared for bronchoscopy by an amethocaine lozenge and topical amethocaine $(2 \%)$ to the pharynx and larynx while on the catheter table. A Negus bronchoscope was then introduced, the patient remaining supine on the table. The exact site of needle puncture was settled in advance after studying the radiological anatomy of the left atrium, carina, and left main bronchus, and was confirmed by direct inspection: the point selected lay between 1 and $5 \mathrm{~mm}$. distal to the carina on the medial wall of the left main bronchus. When the atrium was small, the more distal area was chosen and the needle was directed somewhat medially; but this was not necessary when the atrium was large and the carinal angle wide. By inserting the needle about half-way between the anterior and posterior walls of the left main bronchus, the pulmonary artery anteriorly and the œsophagus posteriorly were avoided.

After passing the bronchoscope, the manometric zero point was readjusted to sternal angle level and the catheter was again advanced until it blocked a peripheral pulmonary artery. When a satisfactory P.C.V.P. tracing was obtained, the bronchoscopy needle was flushed with saline and then pushed through the bronchial wall into the left atrium, and this position was at once confirmed by recording a left atrial pressure curve. In all instances the left atrium was easily entered.

Using the three-way tap, pressure tracings were obtained from the left atrium and from a blocked peripheral pulmonary artery in immediate succession without pause. Electrical mean pressures were recorded from both sites in the same way, and these procedures were then repeated while the patient stopped breathing at the resting respiratory level. The needle and bronchoscope were then withdrawn.

\section{RESULTS}

Pressure measurements and relevant clinical data are recorded in Table I. Cases 4 and 5 represent examples of high pulmonary artery pressure and increased pulmonary arteriolar resistance (Fig. 2 and 3). A normal pulmonary artery pressure and pulmonary arteriolar resistance were 
TABLE I

Pulmonary Capillary Venous Pressures and left Atrial Pressures

\begin{tabular}{|c|c|c|c|c|c|c|c|c|c|c|c|c|}
\hline \multicolumn{3}{|c|}{ Clinical data } & \multicolumn{6}{|c|}{ Resting state before bronchoscopy } & \multicolumn{4}{|c|}{ Bronchoscope in position } \\
\hline \multirow{2}{*}{$\begin{array}{l}\text { Case } \\
\text { No. }\end{array}$} & \multirow{2}{*}{$\begin{array}{c}\text { Age } \\
\text { and } \\
\text { sex }\end{array}$} & \multirow{2}{*}{ Diagnosis } & \multicolumn{2}{|c|}{ P.A.P. } & \multicolumn{2}{|c|}{ P.C.V.P. } & \multirow{2}{*}{$\begin{array}{c}\text { Cardiac } \\
\text { output } \\
\text { (Litres/ } \\
\text { min.) }\end{array}$} & \multirow{2}{*}{$\begin{array}{l}\text { Pulmonary } \\
\text { arteriolar } \\
\text { resistance } \\
\text { (Dynes } \\
\text { sec. cm. }-5 \text { ) }\end{array}$} & \multirow{2}{*}{$\underset{\text { P.C.V.P. }}{\text { S/D }}$} & \multirow{2}{*}{ L.A.P. } & \multirow{2}{*}{$\underset{\mathbf{M}}{\text { P.C.V.P. }}$} & \multirow{2}{*}{$\underset{\mathbf{M}}{\text { L.A.P }}$} \\
\hline & & & S/D & $\mathbf{M}$ & S/D & $\mathbf{M}$ & & & & & & \\
\hline 1 & $\begin{array}{c}42 \\
F\end{array}$ & $\begin{array}{l}\text { M.S., A.S. and } \\
\text { A.I., N.R. }\end{array}$ & $22 / 14$ & 16 & $11 / 7$ & 8 & $6 \cdot 8$ & 94 & $20 / 16$ & $22 / 14$ & 16 & 16 \\
\hline 2 & $\begin{array}{c}46 \\
F\end{array}$ & M.S., N.R. & $52 / 25$ & 35 & $25 / 18$ & 20 & $4 \cdot 3$ & 279 & $27 / 18$ & $25 / 22$ & 19 & 18 \\
\hline 3 & $\begin{array}{l}44 \\
\mathbf{M}\end{array}$ & $\begin{array}{l}\text { M.S., T.S., Aur. } \\
\text { Fibr. }\end{array}$ & $24 / 15$ & 20 & $10 / 8$ & 9 & $3 \cdot 4$ & 259 & $9 / 7$ & $9 / 6$ & 9 & 9 \\
\hline 4 & $\begin{array}{l}34 \\
F\end{array}$ & M.S., Aur. Fibr. & $75 / 38$ & 52 & $35 / 20$ & 25 & $3 \cdot 1$ & 697 & $36 / 22$ & $36 / 22$ & 27 & 27 \\
\hline 5 & $\begin{array}{l}40 \\
F\end{array}$ & M.S., Aur. Fibr. & $110 / 60$ & 75 & $33 / 28$ & 30 & $2 \cdot 8$ & 1,288 & $23 / 14$ & $25 / 13$ & 18 & 18 \\
\hline 6 & $\begin{array}{l}42 \\
\mathbf{M}\end{array}$ & $\begin{array}{l}\text { M.S. and M.I., } \\
\text { A.S., Aur. Fibr. }\end{array}$ & $27 / 13$ & 20 & $19 / 10$ & 13 & $3 \cdot 3$ & 169 & $30 / 11$ & $30 / 11$ & 15 & 15 \\
\hline 7 & $\begin{array}{c}39 \\
F\end{array}$ & M.I., Aur. Fibr. & $21 / 11$ & 16 & $20 / 8$ & 13 & $2 \cdot 2$ & 109 & $33 / 11$ & $30 / 11$ & 17 & 17 \\
\hline
\end{tabular}

All pressures recorded in $\mathrm{mm}$. $\mathrm{Hg}$.

$\begin{array}{ll}\text { P.A.P. } & =\text { Pulmonary arterial pressure. } \\ \text { P.C.V.P. } & =\text { Pulmonary capillary venous pressure. } \\ \text { L.A.P. } & \text { =Left atrial pressure. } \\ \text { S/D } & \text { =Systolic and diastolic pressures. } \\ \text { M } & =\text { Mean pressure. } \\ \text { M.S. and M.I. } & =\text { Mitral stenosis and mitral incompetence. } \\ \text { T.S. } & =\text { Tricuspid stenosis. } \\ \text { A.S. and A.I. } & =\text { Aortic stenosis and aort: incompetence. } \\ \text { N.R. } & =\text { Normal sinus rhythm. } \\ \text { Aur. Fibr. } & =\text { Auricular fibrillation. }\end{array}$

$\begin{aligned} & \text { Aur. Fibr. } \\ & \text { Pulmonary arteriolar resistance is calculated from the Poiseuille equation, Resistance }\end{aligned}=\frac{\text { Pressure gradient }}{\text { Rate of blood flow }}$, and is expressed in dynes second $\mathrm{cm}^{-5}$ (Gorlin, 1951).

found in Cases 1, 6, and 7. Passive pulmonary hypertension and a slight increase of pulmonary arteriolar resistance were found in Case 2. Case 3 was of special interest because of the catheter demonstration of a previously undiagnosed tricuspid stenosis, which was presumed to be partly responsible for the relatively low pulmonary artery pressure and P.C.V.P. (Fig. 5). The mean left atrial pressure and P.C.V.P. agreed closely in each case regardless of the pressure level recorded.

All P.C.V.P. tracings showed venous pulse waves similar in form to those recorded directly from the left atrium. In the two cases with sinus rhythm typical $a$ and $v$ waves were recorded from both sites (Fig. 4). Auricular fibrillation was present in five cases. In these there were no $a$ waves but good $v$ waves were seen in both sets of tracings, each resembling its counterpart very closely in form and amplitude. Left atrial pressure pulses showed small $c$ waves regardless of the rhythm, but these were less evident in P.C.V.P. records (Fig. 3A, 6, and 7).

All pressure waves obtained from a blocked peripheral pulmonary artery showed a delay of from 0.02 to $0.08 \mathrm{sec}$. when timed in relation to corresponding waves from the left atrium. 


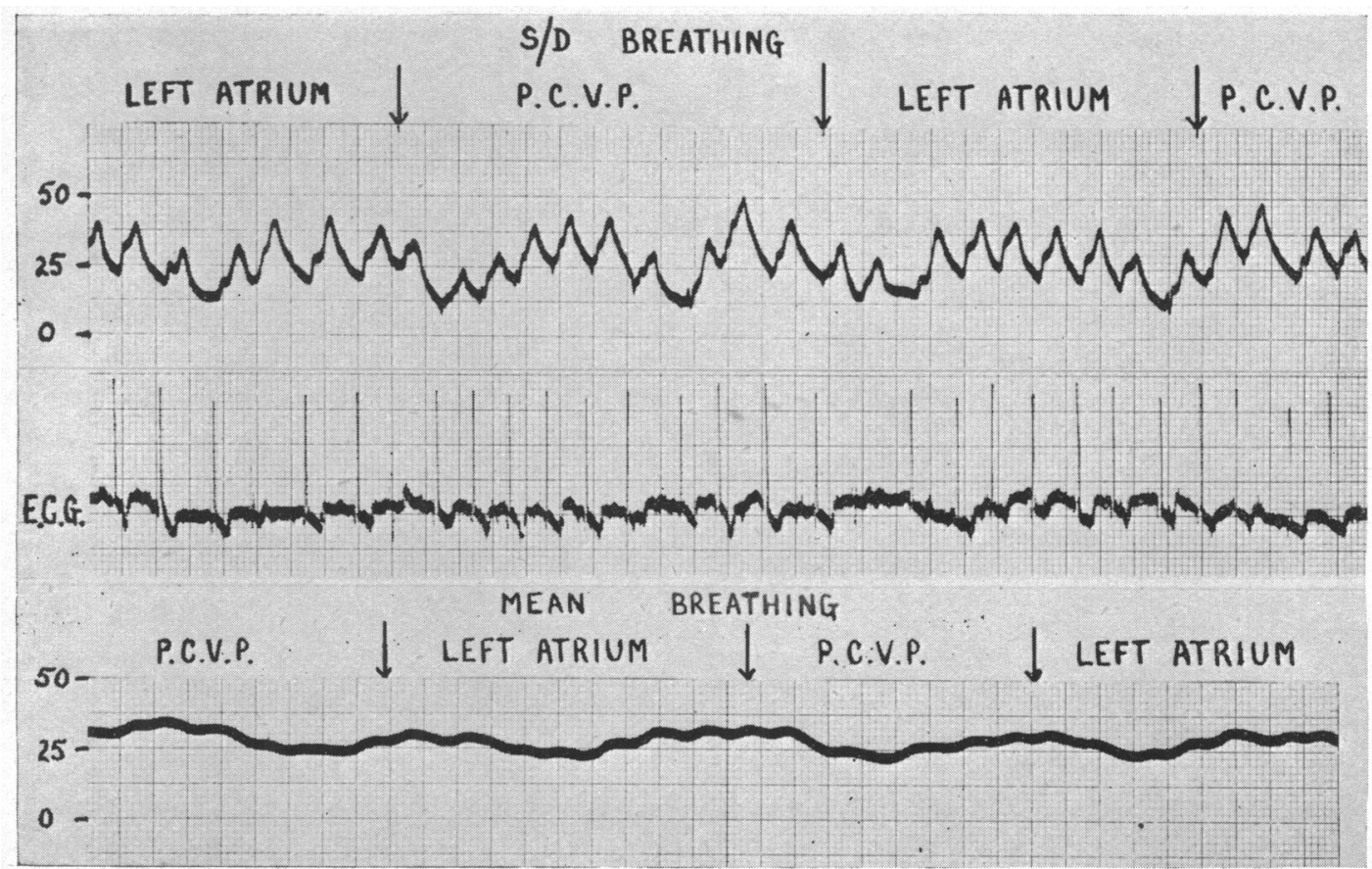

Fig. 2. - Systolic, diastolic, and mean pressure tracings recorded in immediate succession from left atrium and blocked peripheral pulmonary artery. The equality of the pressures is shown. Note the undulating pressure fluctuations related to breathing. Instant of tap switch is marked by arrow. Paper speed $10 \mathrm{~mm}$. a second (Case 4).

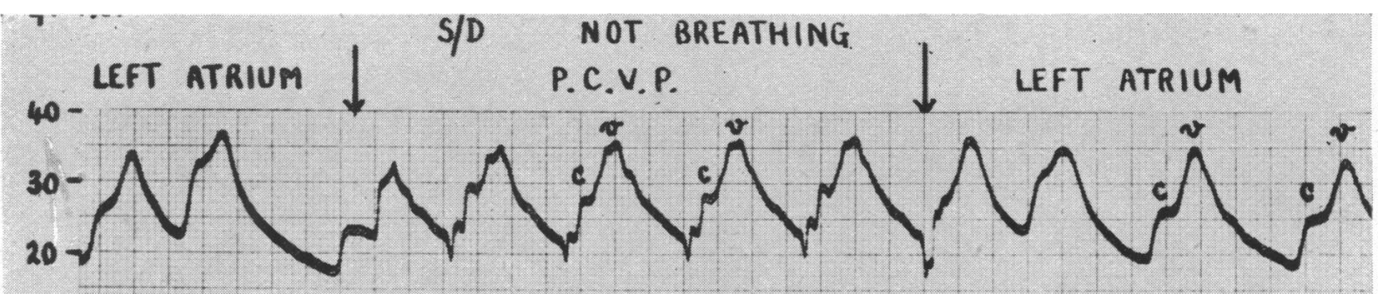

A 10

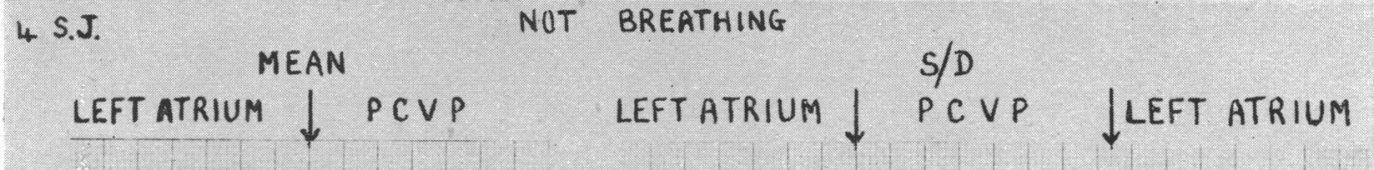

B

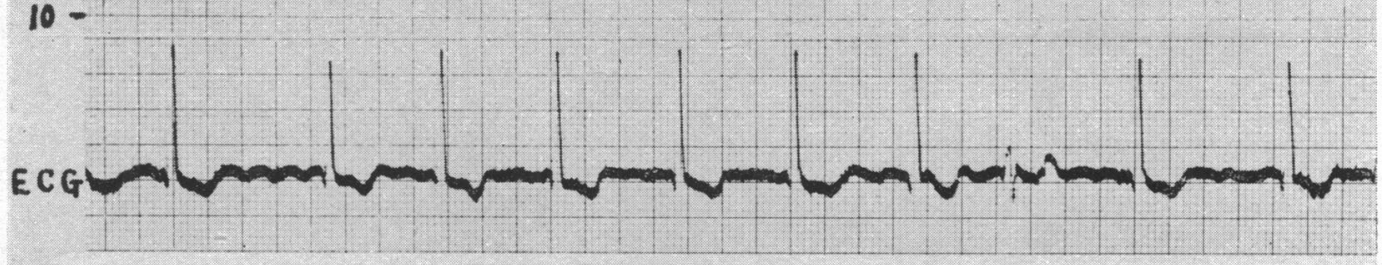

$$
4 \text { S.J. }
$$

\section{NOT BREATHING}

FIG. 3.-(A) Record of immediately consecutive pressure tracings in auricular fibrillation, showing similarity of venous wave pattern (see text). Instant of tap switch is marked by arrow. Paper speed $25 \mathrm{~mm}$. a second (Case 4). (B) Immediately consecutive pressure records in a case with auricular fibrillation showing equal systolic, diastolic, and mean pressures in blocked peripheral pulmonary artery and left atrium. Instant of tap switch is marked by arrow. Paper speed $10 \mathrm{~mm}$. a second (Case 4). 


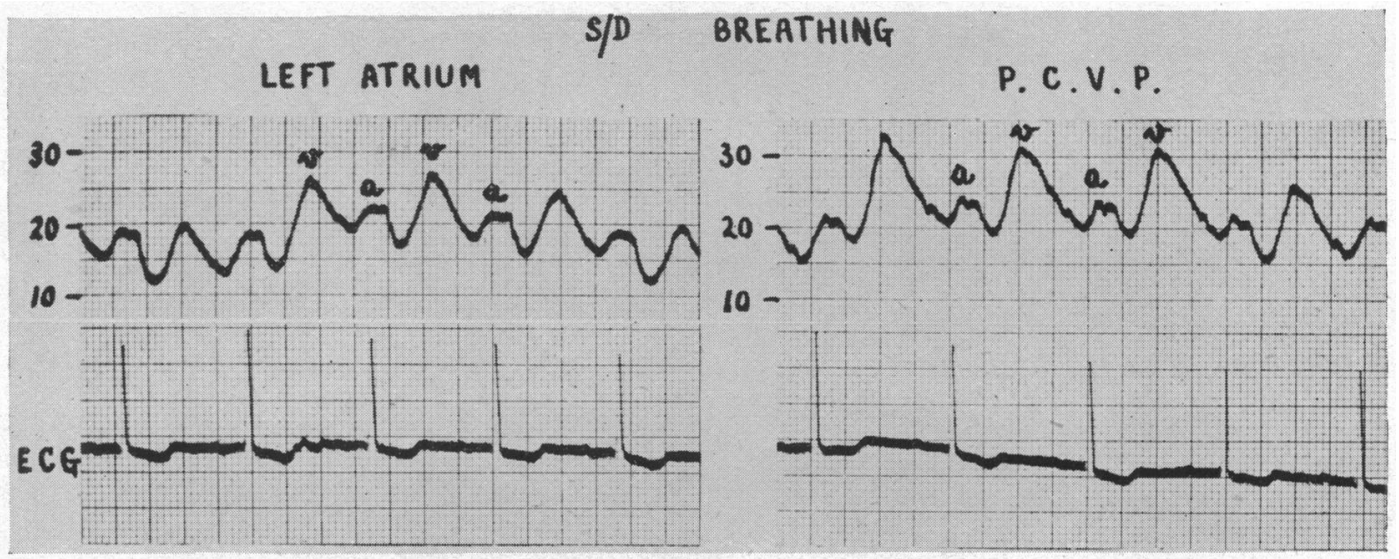

Fig. 4.-Pressure tracings from blocked peripheral pulmonary artery and left atrium with sinus rhythm to show similarity of venous pulse wave (see text). The pressures are not immediately consecutive. Paper speed $25 \mathrm{~mm}$. a second (Case 2).

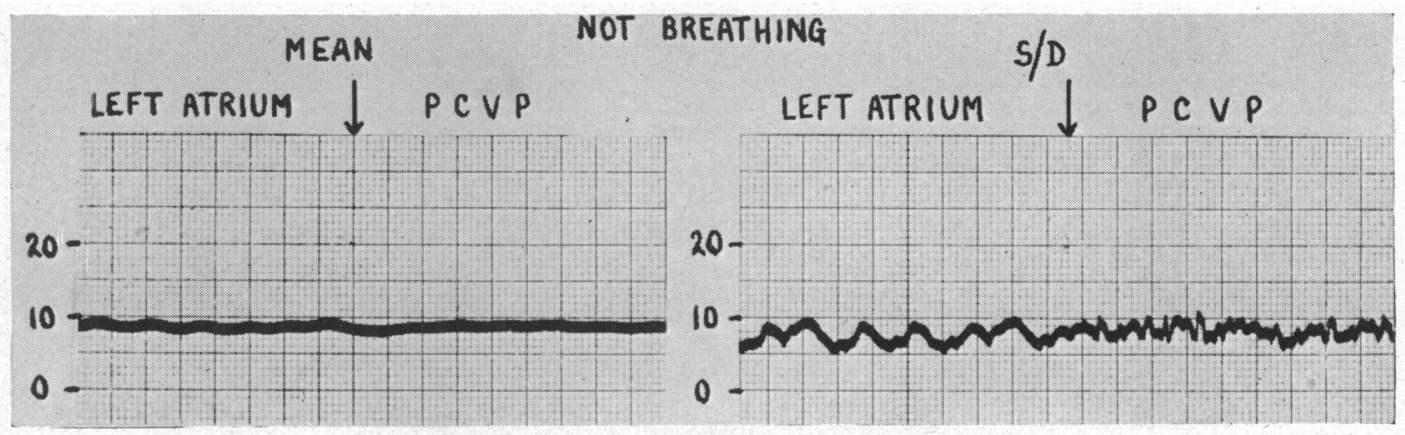

FIG. 5.-Immediately consecutive pressure tracings from blocked peripheral pulmonary artery and left atrium in a case with auricular fibrillation showing identical pressures. This is the only case with a P.C.V.P. venous pulse wave that was not shown clearly (see text). Instant of tap switch is marked by arrow. Paper speed $10 \mathrm{~mm}$. a second (Case 3).

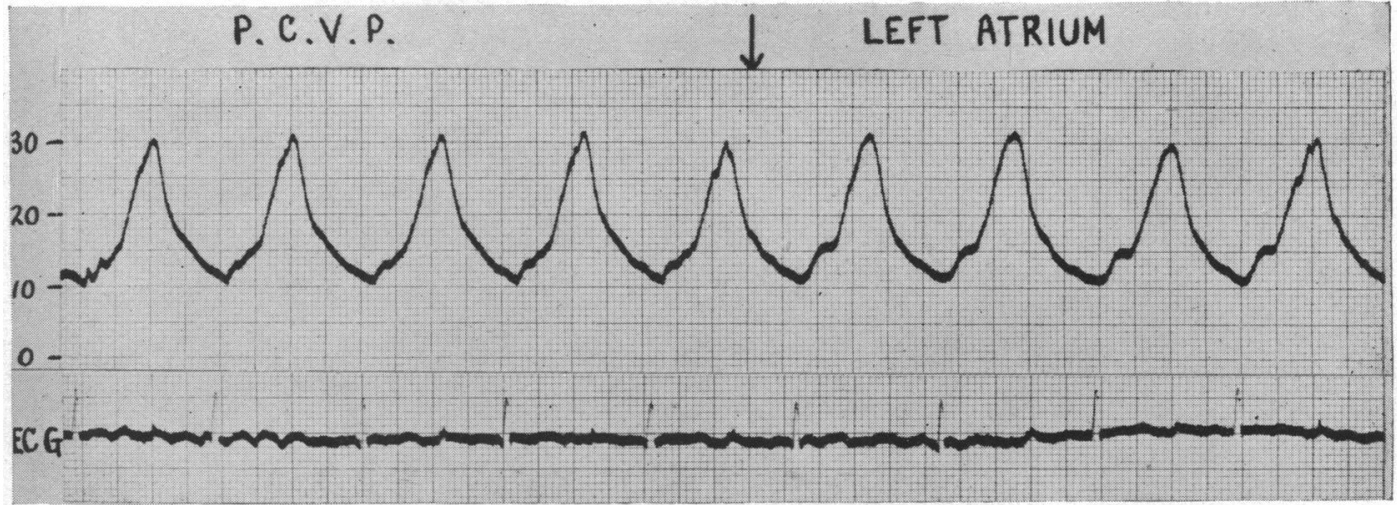

FIG. 6.-Immediately consecutive pressure record from left atrium and blocked peripheral pulmonary artery in mitral stenosis and regurgitation with auricular fibrillation to show similarity of pressure and wave pattern. Instant of tap switch is marked by arrow. Paper speed $25 \mathrm{~mm}$. a second (Case 6). 


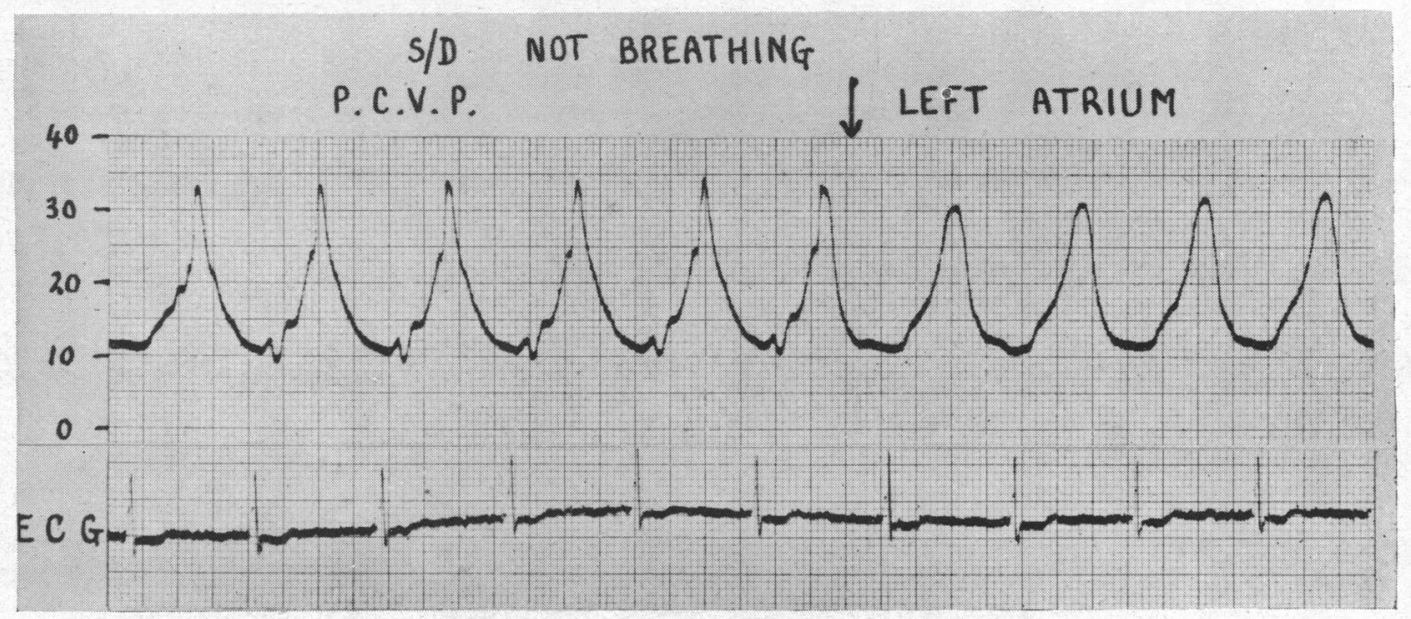

FIG. 7.-Immediately consecutive pressure tracing from left atrium and blocked peripheral pulmonary artery in mitral incompetence with auricular fibrillation showing the type of venous pattern recorded. The mean pressures were identical (see text). Instant of tap switch is marked by arrow. Paper speed $25 \mathrm{~mm}$. a second (Case 7).

\section{DisCuSSION}

For the purpose of this study, cases were specially selected to include examples of sinus rhythm, auricular fibrillation, low and high left atrial pressures, and low and high pulmonary arteriolar resistances. One case of pure mitral incompetence was included.

We have been greatly impressed by the marked lability of the left atrial pressure and P.C.V.P. in relation to the phases of respiration and to minor variations in the resting physiological state of the patient. Misleading figures could easily be obtained in comparing these two pressure records unless simultaneous or immediately consecutive tracings were taken. In general there was a considerable rise in P.C.V.P. during insertion of the bronchoscope, followed by a slow return to the resting level.

Proper damping is essential in obtaining accurate pressure curves. Although some difficulty in this respect was encountered, since accurate tracings had to be recorded from two different sites and through two different systems in rapid succession, critical damping was achieved in most instances (Fig. 3 and 6). Mean pressures were not subject to damping errors and gave convincing proof that P.C.V. and left atrial pressures were identical in all the cases studied.

From previous catheter studies in mitral stenosis carried out in this department, it has long been maintained that a proper P.C.V.P. tracing should be venous in form (Wood, 1952), and the evidence now presented shows clearly that these waves are derived from the left atrium (Fig. 4). In the presence of auricular fibrillation there can be no $a$ wave but only Mackenzie's ventricular form of the venous pulse, the $v$ wave (Fig. 3 and 6).

Despite proper blocking of a peripheral pulmonary artery by the catheter the typical venous wave pattern may not be present. A low or normal pressure in the left atrium may be associated with $a$ and $v$ waves of such low amplitude that they cannot be detected in the P.C.V.P. tracing, presumably because of the damping effect of the intervening capillaries. Extreme pulmonary vaso-constriction in certain cases of mitral stenosis might also be expected to damp out the venous waves from the P.C.V.P. tracing. However, in Cases 4 and 5 the venous wave pattern was transmitted in full strength under just these conditions.

No immediate or delayed complications from the left atrial puncture were encountered, but two cases showed a considerable rise in P.C.V.P. as a result of inserting the bronchoscope. This emphasizes the potential danger of the procedure, which might well precipitate pulmonary œdema under certain conditions; fortunately this did not occur during the present study. 


\section{SUMMARY}

A method of recording immediately consecutive pressures in a blocked peripheral pulmonary artery (P.C.V.P.) and the left atrium in conscious patients with mitral valve disease is presented. Bronchoscopy was performed during cardiac catheterization and a needle introduced into the left atrium through the medial wall of the left main bronchus. The necessity for recording simultaneous or immediately consecutive pressures from the two sites is emphasized, because of their lability during bronchoscopy.

Seven patients suffering from mitral valve disease were selected to include examples of sinus rhythm, auricular fibrillation, low and high left atrial pressures, and low and high pulmonary arteriolar resistances. Mitral stenosis was present in five cases, mitral stenosis and incompetence in one, and pure mitral incompetence in the seventh.

In every instance the mean pressures in the left atrium and blocked peripheral pulmonary artery were found to be equal, and this confirms the view that the P.C.V.P. measured by cardiac catheterization is an accurate measurement of the left atrial pressure in mitral valve disease.

The P.C.V.P. tracing showed venous pulse waves similar in form to those recorded directly from the left atrium in every case, confirming the view that the true P.C.V.P. tracing should be venous in form and that the waves recorded are derived from the left atrium.

The authors wish to give grateful acknowledgment to Dr. Paul Wood for his encouragement during the investigation, and advice in the preparation of this paper. They also wish to express their appreciation for the technical assistance of Miss P. Scarlett, Miss D. Anderson, and Mr. J. Manders.

\section{REFERENCES}

Allison, P. R. (1952). Personal communication.

Ankeney, J. L. (1952). Amer. J. Physiol., 169, 40.

Calazel, R. R., Gerard, R., Daley, R., Daley, A., Foster, J., and Bing, R. (1952. Bull. Johns Hopkins Hosp., 88, 20.

Dexter, L., Dow, J. W., Haynes, F. W., Whittenberger, J. L., Ferris, B. G., Goodale, W. T., Hellems, H. K. (1950). J. Clin. Invest., 29, 602.

Dow, J. W., and Gorlin, R. (1950). Fed. Proc., 9, 33.

Gorlin, R., Haynes, F. W., Goodale, W. T., Sawyer, C. G., Dow, J. W., Dexter, L. (1951). Amer. Heart J., $41,30$.

—, Lewis, B. M., Haynes, F. W., Dexter, L. (1952). Amer. Heart J., 43, 357.

$-1,-1$, Spiegl, R. J., and Dexter, L. (1951). Amer. Heart J., 41, 834.

Hellems, H. K., Haynes, F. W., and Dexter, L. (1949). J. App. Physiol., 2, 24. and Kinney, T. D. (1948). Amer. J. Physiol., 155, 98.

Lagerlöf, H., and Werkö, L. (1949). Scand. J. Clin. Lab. Invest., 1, 147.

Lewis, B. M., Gorlin, R., Houssay, H. J., Haynes, F. W., Dexter, L. (1952). Amer. Heart J., 43, 2.

Mackenzie, J. (1902). The Study of the Pulse. Young J., Pentland, Edinburgh.

Wood, P. (1952). European Congress of Cardiology, Abstracts of Scientific Communications, p. 25. 